Journal of Biogeography

August 2018, Volume 45 Issue 8 Pages 1818-1832

http://dx.doi.org/10.1111/ibi.13381

http://archimer.ifremer.fr/doc/00455/56668/

(c) 2018 John Wiley \& Sons Ltd

\title{
Scale-dependency of the environmental influence on fish $\beta$ - diversity: Implications for ecoregionalization and conservation
}

\author{
Garcia Jessica ${ }^{1,{ }^{*}}$, Pelletier Dominique ${ }^{1}$, Carpentier Liliane ${ }^{1}$, Roman William ${ }^{1}$, Bockel Thomas ${ }^{1}$
}

${ }^{1}$ Unité de Recherche Lagons; Ecosystèmes et Aquaculture Durable en Nouvelle Calédonie (LEAD-NC), Ifremer; Nouméa New Caledonia

* Corresponding author : Jessica Garcia, email address : jessicagarcia.mpa@gmail.com

\begin{abstract}
:
Aim

To determine the ecoregions (spatial marine areas with similar environmental and physical conditions associated with relatively homogeneous fish assemblages) for shallow reef fish assemblages based on predictive models of beta diversity ( $\beta$-diversity) that account for both large-scale environmental factors and local habitat characteristics. We assessed the influence of a spatial scale to rank the importance of these factors.

Location

New Caledonian (south-west Pacific Ocean, $17-24^{\circ} \mathrm{S}, 158-172^{\circ} \mathrm{W}$ ) Exclusive Economic Zone, Coral Sea Marine Park.

Taxon

Fish.

Methods

Fish and habitat data that were collected at 13 sites around New Caledonia using unbaited rotating underwater video (285 sampling stations) were analysed. Gradient forest modelling was used to predict the fish $\beta$-diversity along the gradients of environmental factors. Ecoregions were obtained by applying clustering methods to gradient forest predictions.
\end{abstract}

Results

The gradient forest models of $\beta$-diversity retained 59 species (total: 206 fish species) with $R^{2}>0$, 
including 19 fish species with $\mathrm{R}^{2}$ from $0.03 \%$ to $69 \%$. For these 19 species, the models explained up to $26 \%$ of the variance. At a large scale, $\beta$-diversity was significantly explained by nutrient concentrations, sea surface salinity and temperature. Among the eight ecoregions that were delineated based on the $\beta$ diversity predictions, three regions corresponded to remote sites under oceanic influence where human pressures are low and the surface nutrient concentrations are high. On the local scale, the benthic habitat explained $\beta$-diversity better than the physical and chemical parameters, particularly in the areas subject to anthropogenic pressures.

Main conclusions

On the local scale, the respective importance of environmental factors (physical and chemical parameters versus benthic habitat) differed according to ecosystem health. Our findings suggest that nutrient enrichment due to avifauna may have a positive effect on fish $\beta$-diversity when an ecosystem is healthy. The ecoregions reflect fish species composition in relation to a large set of environmental parameters.

Keywords: $\beta$-diversity, ecoregion, gradient forest, marine biodiversity, New Caledonia, scaledependency, species turnover, underwater video 


\section{ACKNOWLEDGEMENTS}

18 We thank the many people who helped with the fieldwork and image analysis, particularly

19 Gilles Hervé, Delphine Mallet, Kévin Leleu, Nicolas Guilpart, Miguel Clarke, Napoléon

20 Colombani, Jérémie Drelon, and Matthieu Boureau. Most data were collected over the

21 AMBIO project funded by both IFREMER, New Caledonia Government and Provinces, the

22 Conservatoire des Espaces Naturels of New Caledonia, and the French Ministry of Ecology,

23 the French Initiative for Coral Reefs (IFRECOR), and the French Marine Protected Area

24 Agency. Part of the data was collected during the PAMPA project and with the help of the

25 Research Institute for Development. 
59 Beta diversity ( $\beta$-diversity) describes the spatial variation in species composition at different

60 spatial and temporal scales, e.g., in relation to environmental gradients (Barton et al., 2013).

$61 \beta$-diversity is key for conservation science and understanding ecosystem dynamics, the

62 scaling of diversity, and the delineation of biotic regions (McKnight et al., 2007). $\beta$-diversity

63 been defined in multiple ways (Anderson et al., 2011). Commonly, $\beta$-diversity has two main

64 components: the spatial turnover of species (species composition, which accounts for species replacement) and the nestedness of assemblages, which accounts for species loss (more details

66 in Fig. 1 in Baselga (2010)). $\beta$-diversity can be calculated in different ways using

67 similarity/dissimilarity measures, as summarized in Baselga (2010). These measures are based

68 on presence/absence data and not abundance data. In this study, we use the term $\beta$-diversity to

69 depict the spatial variation in fish assemblage based on a species abundance matrix. They are

70 not used here; rather, the term $\beta$-diversity is used to depict the spatial variation in the species

71 composition of an assemblage based on the per species abundance matrix. $\beta$-diversity is commonly used to define ecoregions, which are relatively homogeneous

73 geographical units and distinct from one another (Growns, 2009a). Delineating marine

74 ecoregions is difficult (Lourie \& Vincent, 2004; Kulbicki et al., 2013a) because oceans are 
vast and have no hard boundaries (Baker \& Hollowed, 2014). In this paper, an ecoregion is defined as a spatial marine area with relatively homogeneous species composition that is clearly distinct from adjacent systems (Spalding et al. 2007). Ecoregions are determined within the New Caledonia Exclusive Economic Zone (EEZ), and this differs from Spalding et al. (2007) review paper on marine bioregionalization who defined the term of ecoregions at larger scales, i.e not restricted to one country. Determining ecoregions requires broad-scale analytical tools that can fully utilize ecological data sets and fill corresponding data gaps (Thomson et al., 2014). These requirements are commonly achieved using environmental surrogates, since many studies have shown a close link between the local benthic habitat and the spatial distribution and structure of fish communities (McCoy \& Bell, 1991; Kulbicki, 1997; Sale, 1998; Ferraris et al., 2005), particularly around live coral (Mumby \& Steneck, 2008; Chabanet et al., 2010). Conversely, ecoregions have rarely been determined from fish assemblages (Koubbi et al., 2011; Lasram et al., 2015). In this paper, ecoregions are determined from both environmental and physical conditions and fish species composition. Species distribution models have been developed over the past two decades to model and predict species distributions, primarily from environmental parameters (Guisan \& Thuiller, 2005). Generalized dissimilarity modelling (Ferrier et al., 2007) or gradient forest modelling (Ellis et al., 2012) can be used to analyse and predict $\beta$-diversity based on the entire species assemblage. In gradient forest models, as in other tree-based methods, explanatory factors are hierarchized according to their influence on the response. In our paper, gradient forest modelling is applied to the matrix of species abundances per station to analyse relationships between the spatial variations in abundances per species and environmental variables. Three important features should be considered when modelling the spatial variation of $\beta$ diversity and producing biogeographic predictions: i) the nature of the predictors, ii) the spatial scales and grain (i.e. resolution), and iii) the types of organisms (Barton et al., 2013). 
Barton et al. (2013) noted that biologists often select spatial scales and grains depending on the taxon of interest, its general spatial scale of occurrence and the movement or dispersal capacity of the target species. For example, units were restricted to square centimetres for bacteria (Martiny et al., 2011), square metres for geographic studies on arthropods (Cardoso et al., 2009), and square kilometres for birds (Rahbek, 2005). For biogeographic studies, Spalding et al. (2007) proposed a nested system of spatial units corresponding to realms, provinces and ecoregions.

In terms of conservation and management, historical perceptions and political divisions of marine areas (e.g., EEZ) may not reflect ecological reality (Lourie \& Vincent, 2004), and they may also reveal the technical constraints and costs encountered by scientists and local managers, e.g., when monitoring large areas. The spatial scope of our study is the entire New Caledonia EEZ, which corresponds to a single ecoregion in Spalding et al. (2007). Therefore, our study is conducted at a more local scale than in the cited paper. The study area is approximately $1,740,000 \mathrm{~km}^{2}$ with an extremely long barrier reef (1,600 km long). The unbaited rotating underwater video (STAVIRO) system (Pelletier et al., 2012) used to sample fish and habitat in this large area provides sufficiently fine grain sampling. Moreover, this system is easy to implement and does not require extensive boat or human resources to collect the data.

In this paper, we first quantified the respective influences of environmental parameters (both physical and chemical parameters and local benthic habitat) on fish species composition. Gradient forest modelling was used to conduct this analysis at three nested spatial scales: i) New Caledonia EEZ (>1,400,000 $\left.\mathrm{km}^{2}\right)$; ii) the intermediate scale of the mainland and Chesterfield-Bellona reefs $\left(>1,300 \mathrm{~km}^{2}\right)$, and iii) the local scale $\left(>100 \mathrm{~km}^{2}\right)$.

Our second focus in this paper was to delineate ecoregions across spatial environmental gradients by clustering the gradient forest predictions obtained at the New Caledonia EEZ 
scale. We hypothesized that the reef fish assemblages would be distinct at the isolated reefs and lagoons that are characterized by oceanic influence and low human impact. Several studies suggested that in remote and uninhabited areas, fish assemblages are dominated by predator species, resulting in an inverted biomass pyramid (Stevenson et al., 2007;

Friedlander et al., 2010; Mourier et al., 2016).

\section{MATERIALS AND METHODS}

\section{Study area}

The study area comprises the entire EEZ of New Caledonia (17-24 ${ }^{\circ}, 158-172^{\circ}$ E; Fig. 1), which is characterized by a variety of oceanic and continental coral reefs (Andréfouët et al., 2009). This area comprises (i) a main island $\left(16,500 \mathrm{~km}^{2}\right)$ that is surrounded by a large, highly diversified lagoon subject to a range of anthropogenic pressures, particularly those from Nouméa City; and (ii) remote reefs and atolls under oceanic influence, such as the Chesterfield-Bellona reefs and the Matthew, Hunter and Walpole Islands, which are wellpreserved areas and host large populations of several bird species (Borsa et al., 2010). A large number of lagoons in New Caledonia were included on the UNESCO World Heritage List in 2008 (World Heritage Committee, 2008) because of the exceptionally high diversity of their coral reef ecosystems.

\section{Ecological data collection}

Benthic habitat and fish were sampled by using an unbaited rotating underwater video (STAVIRO system) (Pelletier et al., 2012). These cameras were set to record images for 9 $\min \left(3\right.$ rotations of $3 \mathrm{~min}$ each). During each rotation, the camera rotates $60^{\circ}$ every 30 seconds (6 sectors per rotation). The sampling was performed at 13 sites that are representative of the ecosystems encountered in the Coral Sea Marine Park (CSMP) and on the World Heritage property, both outside of the coastal lagoon (Chesterfield and Bellona, Matthew, Hunter and Walpole) and around the mainland (Nouméa, Koné, Pouebo, Hyenghène, Borendy, Merlet, 
Corne Sud and Ouano) (Fig. 1). We selected a subset of 285 sampling stations that are exclusively located in hard substrate reef habitats and correspond to depths between 2 and 36 m. The data from the majority of the stations $(88 \%)$ in the subset were collected between May 2012 and September 2013. Based on the results of Mallet et al. (2016) and Powell et al. (2016), we selected the 285 sampling stations that were collected between 8 a.m. and 3 p.m. to reduce the possible short-term temporal variations in fish abundance. At each station, each fish that was recorded in a $5 \mathrm{~m}$ radius around the camera was identified to the finest taxonomic level (see Pelletier et al. (2012) for a complete description of the procedure). In our analysis, we retained only individual fish that were identified at the species level. Fish abundance was estimated as the mean number of fish per rotation, which was averaged over the three rotations and scaled to a $100 \mathrm{~m}^{2}$ surface area. Fish abundance data resulting from image analysis were log-transformed before the analysis to correct for distribution skewness.

\section{Environmental predictor parameters}

\section{Local habitat}

At each station, local habitat descriptors were estimated from the same video footage used for the fish, following a method derived from Clua et al. (2006) (see Pelletier et al. 2012 for details). The descriptors consisted of abiotic descriptors (substrate nature and granulometry) and biotic percent covers (living coral, seagrass and macroalgae). The coral cover categories included dead coral and live coral, distinguishing massive and encrusting coral, digitate coral and branching coral. The other habitat categories that were considered in the present study were seagrass, macroalgae, sand, gravel, rock and slab cover. The topography and complexity were scored on a scale that ranged from 0 to 5 (Pelletier et al., 2012), while other habitat categories were percent values. The grain of these local habitat data strictly matched the resolution of the fish data, i.e., it corresponded to the surface of a disc with a radius of $5 \mathrm{~m}$ 
around the STAVIRO system. The local habitat data formed a non-continuous data layer over the study area. To obtain a map of $\beta$-diversity for the entire area, these data had to be interpolated at each cell of the grid that was used to model and predict fish $\beta$-diversity. The interpolation of the local habitat data relied on the inverse distance weighting interpolation (IDW) method (ArcView 10.2 with Spatial Analyst extension, ESRI, Redlands, USA) that conserved the local variations between sample points (Torres et al., 2008). The interpolation was limited to depths shallower than $250 \mathrm{~m}$. Although no fish data were collected at such depths, the $250 \mathrm{~m}$ value was retained to allow for the visualization of external slopes on the map.

\section{Chlorophyll a, physical factors and nutrients}

Twenty-one environmental parameters were considered (Table 1). The sea surface temperature (SST), sea surface salinity (SSS), bathymetry (Bathy), distance to coast (Coast dist), latitude (NSAsp) and longitude (EWAsp) aspects (30 arc-second) were obtained from the MARSPEC dataset (Sbrocco \& Barber, 2013). For the SST and SSS, we considered the annual mean (MeanAnsst, MeanAnsss), annual variance (VrAnsst, VrAnsss) and annual range (RgAnsst, RgAnsss). The maximum and minimum SST values (Maxsst and Minsst) were also considered. The distance to the coast was computed with respect to the closest island, which was either the mainland or the Loyalty Islands. Chlorophyll a concentrations were obtained by using the GES-DISC Interactive Online Visualization and Analysis Infrastructure (Giovanni) at a $9 \mathrm{~km}$ spatial resolution. These data were available for 2007, 2008, 2010 and 2012. Nutrient concentrations (phosphates, nitrates and silicates) were extracted from NOAA's National Center for Environmental information datasets (http://www.noaa.gov/). The corresponding ground truth data were either relatively close $(<50 \mathrm{~km})$ for remote reefs or inside the lagoon for mainland sites. We also utilized the nutrient data from the external slope to characterize the nutrient conditions in this zone. For each nutrient, we retained the surface 
concentration and the mean concentration between $5 \mathrm{~m}$ and $35 \mathrm{~m}$, which were consistent with the depth range of the stations. All environmental variables were mapped on a common grid of $0.024^{\circ}$ in latitude by $0.024^{\circ}$ in longitude.

\section{Gradient forest modelling}

Gradient forest (Ellis et al., 2012) is a non-parametric statistical method that is derived from random forest (RF) modelling (Breiman, 2001; Cutler et al., 2007). Based on a machine learning algorithm, RF evaluates the importance of environmental predictors for each species and determines where significant changes in species composition and abundance occur along the environmental gradients. Gradient forest generalizes the RF method by extending the analysis to the entire species assemblage across a gradient of environmental factors. Similar to $\mathrm{RF}$, gradient forest is statistically robust and involves a large set of regression trees $(>1,000$ trees). Each tree is built by successive dichotomic partitioning of sampling station sets, such that species abundance is as homogeneous as possible within each set. At each stage, partitioning is achieved by selecting a specific split value $v$ for one of the predictors to reduce impurity, i.e., the sum of squared deviations around the set mean (Breiman, 2001; Cutler et al., 2007). The partitions are successively divided in this way until a partition results in a terminal node. The trees are built from bootstrap samples of the response variable (fish abundance), and the nodes are determined by the environmental predictors that better discriminate between the tree branches the differences in the tree branches. For each tree, the data that are not retained in the bootstrap sample are named out-of-bag (OOB) data; they contribute to the cross-validated estimate of the generalization error. In this study, this resampling procedure with replacement was repeated for each tree, and the tree-like structure was recovered. The goodness-of-fit of the model was measured through the proportion of variance explained, $R_{S}^{2}$, for species $s$ as follows.

$$
R_{s}^{2}=\sum_{i}\left(X_{s i}-\hat{X}_{s i}\right)^{2} /\left(X_{s i}-\bar{X}_{s}\right)^{2}
$$


where $X_{s i}$ is the $i$ th abundance observation, $\hat{X}_{s i}$ is the OOB prediction, and $\bar{X}_{s}$ is the mean abundance.

Each RF was divided among the predictor variables as a function of their importance, $I_{s p}$, and among the raw importance values, $I_{s p v t}$. Thus, $I_{s p}$ quantifies the contribution of a predictor to the goodness-of-fit of the model. In practice, $I_{s p}$ is the increase in the prediction error when a predictor $\mathrm{p}$ is randomly permuted. The contribution of predictor $p$ to the goodness-of-fit of a model for species $s\left(R_{s p}^{2}\right)$ is defined as

$$
R_{s p}^{2}=R_{S}^{2} I_{s p} / \sum_{p \prime} I_{s p \prime}
$$

In this paper, gradient forest was used to examine the responses of fish assemblages along environmental gradients, hierarchize the environmental parameters based on their influence on the assemblages and identify the threshold values of the environmental parameters that determine the changes in $\beta$-diversity described by changes in species composition.

Such changes may result from nestedness or spatial turnover, as explained by Baselga (2010). Nestedness and turnover were calculated following the approach proposed in the cited paper. The results showed that $99.6 \%$ of the dissimilarity in our dataset was due to turnover, and thus, nestedness was negligible in our study. Therefore, most of the variation analysed here is considered compositional turnover.

The distribution of the $\mathrm{R}^{2}$ values from all fish species was analysed among the predictors as a function of predictor importance, $I_{s p}$, and along the gradient of values for each predictor as a function of the density of $I_{\text {spvt }}$. This procedure allowed the $\beta$-diversity along the gradient of each environmental predictor p to be determined (see Breiman (2001), Cutler et al. (2007), and Ellis et al. (2012) for the full details of the modelling procedures).

\section{Prediction}


Where fish data were not available, predictions were obtained at all locations where environmental covariates were available. To this end, we used the cumulative importance distributions as empirical functions (see gradientForest predict function). Model-predicted $\beta$ diversity values were then ordinated and visualized through principal component analysis (PCA). At each grid point, a colour was determined from a red-green-blue (RGB) colour palette based on the first three component coordinates. The outcome was mapped over geographical space. Out of the thirteen sites in the initial data set, local gradient forest modelling was performed for eight sites (Chesterfield, Bellona, Merlet, Corne Sud, Pouebo, Koné, Ouano and Nouméa). These sites were selected as they were characterized by contrasting local habitats.

Gradient forest was applied at i) a large scale, including the entire data set (New Caledonian EEZ, 1,400,000 $\mathrm{km}^{2}$ ), ii) an intermediate scale by running separate models for the mainland and for the Chesterfield-Bellona reefs $\left(1,300 \mathrm{~km}^{2}\right)$, and iii) a local scale $\left(100 \mathrm{~km}^{2}\right)$ by modelling the data separately for each survey site. Gradient forest modelling was performed by using R 3.1.2 (gradientForest package in R Core Team, 2014). The gradient forest model outputs for the entire data set were further analysed to define the ecoregions. These outputs correspond to a prediction of fish species composition in each cell of a grid covering the study area. The grid was constructed from the coordinates of the environmental variables (36648 grid points). The gradient forest predicted the fish abundance per species at each grid point where abundance data were not available based on the non-linear response of the fish abundance data to the gradients in the environmental predictors. This way, the environmental predictors were transformed to a multidimensional biological space that could be mapped in geographic space (more details in (Pitcher et al., 2012)). As expressed in other terms by Leaper et al. (2011), "gradient forest provides a transformation from environmental space into a space where distance represents compositional differences". 
271 Ecoregions were then obtained by clustering predictions through a K-means partitioning technique (vegan package in R (Oksanen et al., 2007)). The partitions were determined based on the simple structure index (ssi) criterion. Therefore, each cluster comprised stations that had similar patterns in biological community composition, as predicted by the gradient forest from the environmental parameters. At the regional scale, local habitat cover was visualized for each site by using radar plots (fmsb package in R; (Nakazawa, 2014).

\section{Spatial autocorrelation}

To evaluate the importance of spatial autocorrelation in our results, we used the method of Leaper et al. (2011). These authors used generalized dissymmetry modelling (GDM) with an implementation of the Ferrier et al. (2007) GDM link function. We modelled the Bray-Curtis dissimilarity between the sample stations as a function of the Euclidean distance between the biologically transformed environmental variables at sampling stations, both with and without geographic distance between sampling stations.

Spatial autocorrelation was found to have little influence on the gradient forest results since the difference in variance explained by the model when accounting for geographic distance was small $(0.9 \%)$. Therefore, we ran the model without accounting for the distances between stations.

\section{RESULTS}

\section{Delineation of ecoregions}

A total of 206 species, 56 genera, and 28 families of fish were observed at the 285 sampling stations. The gradient forest model was built from all fish species, but it retained only 59 species with $\mathrm{R}^{2}>0$, of which 19 fish species had $\mathrm{R}^{2}$ values that ranged between $0.03 \%$ and $69 \%$. For these 19 species, the model accounted for up to $26 \%$ of the total variance. These species in decreasing importance were Scarus niger, Paracanthurus hepatus, Siganus doliatus, Chlorurus sordidus, Lethrinus miniatus, Ctenochaetus striatus, Scarus ghobban, 
Parupeneus multifasciatus, Siganus vulpinus, Plectropomus laevis, Acanthurus olivaceus,

Hemigymnus melapterus, Aphareus furca, Bodianus axillaris, Pterocaesio trilineata,

Lethrinus variegatus, Carcharhinus amblyrhynchos, Chaetodon lunulatus, and Ctenochaetus

binotatus. The total variance explained (TVE) was $77 \%$ for the physical and chemical parameters and $23 \%$ for the local habitat. At the large scale, the most influential environmental predictors were phosphate concentrations (surface and 5-35 m), with 15\% of the TVE (Fig. 2a). The next most important factors were the maximum SSS and the annual variance of temperature, which explained $6 \%$ and $5 \%$ of the TVE, respectively. Two other significant parameters were surface silicate (5\% of the TVE) and nitrate (5\% of the TVE) concentrations. Local habitat parameters were less influential than the above predictors.

The model was used to predict the $\beta$-diversity from the 35 environmental and habitat parameters (Fig. 3a). Eight ecoregions were then determined by clustering the $\beta$-diversity from these predictions (Fig. 3b). Ecoregion 1 included the isolated oceanic reefs of Chesterfield (the lagoon and western reef), Entrecasteaux, Hunter and small parts of northwestern Bellona (Fig. 3). This ecoregion was characterized to high surface concentrations of phosphate and nitrate. (Fig. 4; Table 2). Ecoregion 2 corresponded to the deep external slopes of the lagoon were subject to a strong oceanic influence (Fig. 3). This region was the most heterogeneous with large variations in i) surface phosphate, ii) temperature, iii) salinity, and iv) nitrates (Fig. 4; Table 2).

The lagoon that surrounds the main island included ecoregions 3, 8 and 4 (Fig. 4), which are located on a north-south gradient. Ecoregion 3 corresponded to the large Northern Lagoon far from the coastline that is open to oceanic influence, while the southern part of this lagoon was assigned to ecoregion 8 . The latter also comprised lagoon areas on the western and eastern coasts in the northern half of New Caledonia mainland. Compared with ecoregion 3, ecoregion 8 was characterized by relatively high values in salinity, silicate and nitrates (Table 
2). Ecoregion 4 corresponded to the most southern area, including half of the lagoon around the mainland and Pine and Walpole islands. In this ecoregion, nitrates were particularly low (Fig. 4, Table 2).

The other ecoregions corresponded to areas outside the main lagoon. Ecoregion 5 comprised only the north Bellona lagoon and several reef patches that were south of Chesterfield. It was characterized by the same nutrient parameters as ecoregion 1 but had a higher salinity (Table 2). Ecoregion 6 exclusively constituted the Loyalty Islands, and it was identified by low surface concentrations in phosphate and silicate (Fig. 4; Table 2). Ecoregion 7 was represented only by south Bellona and was on average the furthest region from the coastline. Overall, at the large scale, the local habitat did not influence much $\beta$-diversity prediction and ecoregion construction and thus appeared as a secondary explanatory factor compared to nutrients and physical parameters.

\section{Influence of the environmental parameters at the intermediate scale}

Gradient forest modelling was also run separately for two distinct areas, namely, the mainland and Chesterfield-Bellona. For the mainland (Fig. 2b), the physical and chemical predictors explained $66 \%$ of the TVE, while the local habitat variables explained $34 \%$ of it. Phosphate ( $18 \%$ of the TVE), salinity ( $7 \%$ of the TVE) and branching coral cover ( $6 \%$ of the TVE) were the most significant factors that explained $\beta$-diversity (Fig. 2c). For Chesterfield-Bellona (Fig. 2c), the local habitat explained $28 \%$ of the TVE, whereas the physical and chemical predictors explained up to $72 \%$ of the TVE, in particular, the nitrate concentration between $5 \mathrm{~m}$ and 35 m (11\% of the TVE), maximum salinity (9\% of the TVE), mean temperature (9\% of the TVE), and massive and encrusting coral cover ( $8 \%$ of the TVE).

\section{Influence of the environmental parameters at the local scale}

Out of the thirteen sites in the initial data set, gradient forest modelling was performed for eight sites (Chesterfield, Bellona, Merlet, Corne Sud, Pouebo, Koné, Ouano and Nouméa) that 
were characterized by contrasted local habitats (Fig. 5). The average live coral cover was high at the Chesterfield (79\%), Bellona (48\%), Merlet (45\%), Corne Sud (47\%) and Pouebo (53\%) sites (Fig. 5), where a large diversity of coral forms (massive and encrusting coral, digitate coral, branching coral, and hard coral) was observed. At these five sites, the local habitat parameters explained a relatively low proportion of the TVE, with $27 \%$ for Chesterfield, $18 \%$ for Bellona, $12 \%$ for Merlet, 35\% for Corne Sud and 23\% for Pouebo. In contrast, the average live coral cover was lower on the western coast of New Caledonia, i.e., Koné (33\%), Ouano (20\%) and Nouméa (20\%) (Fig. 5). At these three sites, $\beta$-diversity was mainly explained by the local habitat parameters, with $89 \%, 50 \%$ and $98 \%$ of the TVE at Koné, Ouano and Nouméa, respectively. At Ouano, the macroalgae cover was the main predictor.

\section{DISCUSSION}

The first objective of this study was to model the relationships between environmental parameters and fish species composition over a large area encompassing all the reef areas of New Caledonia, which stand together away from other surrounding islands in the Western Pacific. By conducting the analysis at several scales, we showed that these relationships and the respective influences of environmental factors on $\beta$-diversity depended on the geographic scale. To the best of our knowledge, this is the first study considering environmental parameters from both large-scale data and local information about benthic habitat to model and understand $\beta$-diversity patterns in coral reef ecosystems. This method is important because, in such ecosystems, lagoon and reef area habitats are very heterogeneous at small scales, which results in large spatial variations in fish distribution. By accounting for local variations due to habitat, spatial patterns at larger scales, particularly those linked to gradients in nutrients and physical parameters, could be better understood. This understanding was also made possible because data were available for a wide range of benthic habitat conditions with differences in rocky and sandy substrate covers. These data were an important asset for the 
second objective of our study, i.e., determining ecoregions at the study area scale using model predictions obtained at the largest scale. Ecoregions were thus determined from both environmental and physical conditions and fish species composition. Our model explained $26 \%$ of the total variance, which may not seem large but is indeed consistent with results from other studies using gradient forest modelling, with e.g., 30\% (Beazley et al. 2015), 32\% (Booker et al. 2014), 12.4\% (Compton et al. 2012) of the TVE by their respective models. Booker et al. (2014) used an approach by phylum that tends to reduce data variability, and they studied invertebrate communities, which are less mobile than fish. Commonly, local habitat structure highly determined richness and abundance of small sedentary reef fishes (Belmaker et al., 2008; Belmaker, 2009; Messmer et al., 2011). These studies mainly focused on fish species closely associated with coral (e.g: gobies, damselfishes and juveniles) and at a really small range. The 19 species retained in the model are mobile within their range, but most of them are generally considered as living in a restricted reef area (in contrast e.g. to pelagic species) but still exhibit a larger range than species closely associated with live coral. Consequently it is likely that the fish species in our study are less sensitive to live coral cover, one of the local habitat variables, than the species studied in these three studies.

A major outcome of our models is that the respective influences of environmental factors on $\beta$-diversity depend on the scale of analysis. This finding is discussed below, first through the link between local habitat and ecosystem health in coastal areas and second through natural enhancement in nutrients on oceanic reefs. The last part of the discussion addresses the determination of ecoregions.

\section{Hierarchical importance of environmental factors depends on both scale and ecosystem}

\section{health}


In the models per site, the proportion of variance explained (TVE) by environmental factors strongly differed among the sites, and in particular, this variance ranged from $12 \%$ to $98 \%$ for the local habitat factor. The results obtained at the site scale demonstrated that the links between $\beta$-diversity and local habitat (coral, seagrass and macroalgae) depended on the health of the local ecosystem. Live corals play a crucial role in the functioning of coral reef ecosystems, and healthy coral reef ecosystems are characterized by a dominance of live coral. Coral reef ecosystems may be impacted by many drivers and events, including global warming, ocean acidification, storms, trophic-level dysfunction, eutrophication and other anthropogenic factors. These ecosystems are vulnerable to sudden events that can induce a phase shift in the community structure from coral-dominated to algal-dominated systems (Mumby \& Steneck, 2008). Macroalgae biomass hinders and obstructs coral recruitment (Kuffner et al., 2006) and inhibits coral growth (Tanner, 1995) and fecundity (Foster et al., 2008). The ecoregions obtained here correspond to three health statuses for coral ecosystems (Fig. 4): i) atoll reefs with no human impacts that are dominated by live coral (the Chesterfield and Bellona reefs), ii) reefs closer to the coast that are dominated by live coral (Merlet, Corne Sud and Pouebo), and iii) coastal reefs where the macroalgae cover was higher, such as Ouano and Nouméa and, to a lesser extent, Koné. In moderate areas of eutrophication, where coral-dominated ecosystems influenced fish diversity by increasing phytoplankton biomass and macroalgae, the herbivory biomass was sufficient to regulate algae production (Burkepile \& Hay, 2006). In contrast, on macroalgaedominated reefs, a similar eutrophication level explained less species turnover than the local habitat. This finding was consistent with the fact that in the absence of suitable habitat, fish abundance and diversity are significantly reduced, particularly for the species that strongly depend on live coral for settlement habitat or food (Mumby \& Steneck, 2008). Airoldi et al. (2008) showed that anthropogenic disturbances reduced habitat complexity and diversity and 
resulted in the decline of resident species and food resources, and such environmental homogenization can greatly impact fish diversity.

Therefore, the influence of nutrients on $\beta$-diversity appeared to be dependent on ecosystem health. Local habitat was a critical factor in explaining $\beta$-diversity in areas where anthropogenic pressures were high, while the nutrient influence was low in these areas. We hypothesized that in these situations, ecosystem eutrophication is a secondary factor that influences fish $\beta$-diversity. At a local scale, the preservation of a healthy habitat may thus increase the resistance of an ecosystem to eutrophication, with a moderate nutrient enrichment (of a natural or anthropogenic origin) having a positive impact on fish diversity in healthy habitats.

\section{Natural enhancement of nutrients on oceanic reefs}

On oceanic reefs, the outcomes of models contrasting remote reefs with sites located within the mainland lagoon indicated a strong influence of nutrients on fish $\beta$-diversity. Phosphate and nitrate concentrations were particularly high (Fig. 5) in the ecoregions that corresponded to remote reefs and islands, such as Chesterfield and Bellona, Entrecasteaux, Matthew, and Hunter. The corresponding nutrient data points were close to the reef. These results are consistent with the hypothesis of an "island mass effect" (IME) (Gove et al., 2016), which depicts the increase of phytoplankton biomass near island-reef ecosystems in oligotrophic tropical oceans. In the lagoons of oceanic atolls, an IME may result from waves and tidaldriven flushing into enclosed waters (Gove et al., 2016). These isolated reefs and atolls are uninhabited and have low anthropogenic impacts. However, these locations are home to abundant sea bird populations that produce large quantities of guano, which is rich in both organic nitrate and phosphate. In fact, Chesterfield, Bellona and Entrecasteaux were exploited for guano extraction (Clua et al., 2015) in the 1870s. The phosphate origin may be mineral or organic (including anthropogenic). Although several studies have been conducted since the 
beginning of phosphate exploitation at New Caledonian reefs and islands, none of these studies found evidence of mineral phosphate at these reefs (Delvinquier \& Jegat, 2001). In addition to the well-known sources of nutrients, animal waste products (e.g., from sea birds, reef-associated fish and mobile marine invertebrates) may substantially contribute to the nutrients in coral reef ecosystems (Gove et al., 2016). McCauley et al. (2012) also observed the fertilization of soil and an increase in coastal nutrients due to sea birds. Oceanic ecoregions (i.e., ecoregions 1, 5 and 7) correspond to coral reef ecosystems in very good health, with high proportions of living coral, high diversities of coral shapes and high fish diversities. These regions may thus be considered quasi-pristine areas, where continuous eutrophication naturally occurs from avifauna dejection and where such eutrophication is likely to be dispersed or absorbed by the coral reef ecosystem. Complex ecological mechanisms ruling the dynamics of coral reefs represent a major scientific challenge. Our results are consistent with the hypothesis that where ecosystem health is good, substantial nutrient enrichment and oceanic current may be integrated by the ecosystem.

The results for the Chesterfield and Bellona islands show that terrestrial and marine fauna were highly linked, which demonstrates the importance of preserving the entire ecosystem. Many studies showed that anthropogenic activities, i.e., eutrophication, led to strong impacts on benthic communities with an increase in algal cover, which is detrimental to live coral (Fichez et al., 2005; Littler et al., 2006; Allgeier et al., 2017). This habitat degradation impacts a fish assemblage via a rise of detritivores and herbivorous fishes (Khalaf \& Kochzius, 2002) such as scarids, pomacentrids and acanthurids. Eutrophication can also impact juvenile fish sensitive to chemical cues (Chabanet et al., 1995) or adults by favouring parasites. In our study, we showed that $\beta$-diversity is influenced by multiple factors and could be inducing a strong impact (positive or negative) on the functions of the coral reef ecosystem. 


\section{Ecoregion delineation and implications for conservation}

This study provides the first delineation of ecoregions based on both fish species turnover and environmental parameters at the scale of an entire archipelago encompassing both remote and coastal areas. Ecoregion identification is important for conservation planning, and in this area included in the CSMP, $\beta$-diversity was identified as a gap in the initial knowledge base assessment (Ceccarelli et al., 2013). Eight ecoregions were determined from both fish community data and many environmental parameters, including physical, chemical and nutrient parameters, as well as local habitat data. The data that were used pertained to areas with contrasting fish assemblages and natural and anthropogenic pressures, which allowed better model predictions. The nearly pristine areas that were considered here provided original information for a better understanding of how environmental factors naturally shape fish diversity. The first study to define biogeographical delimitations was that of Ekman (1953), which was based on zoogeographical parameters, environmental barriers and levels of endemism. Other studies have demonstrated that the presence of natural barriers, such as the Red Sea land bridge and the Isthmus of Panama, results in biogeographical delimitations (Bellwood \& Wainwright, 2002). Recently, Kulbicki et al. (2013) proposed six large marine regions in the world based on reef fish assemblage data. These studies brought important insights into the spatial patterns and dynamics of these ecosystems. In Spalding et al. (2007), New Caledonia is a single ecoregion. In the present study, ecoregions were determined within New Caledonia EEZ, and thus, the spatial extent is smaller than in the references above. However, the definition of an ecoregion remains that of Spalding et al. (2007): "a spatial marine area with relatively homogeneous species composition that is clearly distinct from adjacent systems". The spatial extent of our study corresponds to a well-identified natural entity in the Western Pacific and applies to a management setting that is relevant for both the New Caledonian archipelago and the CSMP. Furthermore, this study is located in marine 
495

496

497

498

499

500

501

502

503

504

505

506

507

508

509

510

511

512

513

areas that are among the most preserved in the world. The exceptional diversity of coral and fish species, healthy populations of large predators, and considerable number and diversity of large fish in this area were the main criteria for inscribing $80 \%$ of the New Caledonian reef and lagoon areas on the World Heritage List (http://whc.unesco.org/en/documents/115088/). Management and conservation issues always imply actions at several scales (Kittinger et al., 2011 for a Pacific case study). The different management types are interconnected at local and regional scales, and they rely on the same scientific evidence for policy making; the findings of this study provide original knowledge at three distinct scales. The results per site pertain to local management by New Caledonian provinces, corresponding to the implementation and assessment of marine reserves. The other results are relevant for regional management, and they are also useful for putting all the sites into perspective and providing contrast between remote sites that can be considered reference health statuses and coastal areas that are subject to stronger anthropogenic pressures. This analysis brings new insight into understanding human impacts on marine ecosystems by comparing almost pristine areas with urbanized coastal areas. At the scale of the lagoon surrounding the main island, our results may document conservation planning for the establishment or consolidation of a network of marine protected areas including the maximal diversity of species or ecosystems (Growns, 2009).

Table 1 Environmental predictor variables used for the gradient forest modelling.

\begin{tabular}{lllll}
\hline Parameters & Environmental & Abbrev. & Units & Source \\
& parameters & & & \\
\hline Local habitat & Live coral & -- & $\%$ & AMBIO project \\
& Dead coral & -- & \\
& Hard coral & -- & \\
& Massive and encrusting & Mass_Enc_Cor & & \\
& coral & & &
\end{tabular}


Digitate coral

Branch coral

Seagrass

Macroalgae

Sand

Slab

Rocks

Gravel

Topography

Complexity

Bathymetry

Latitude and longitude

Depth

East/west orientation

Bathy

EWAsp

Metres

Radians

aspects

Coastal line

Sea surface temperature

(SST)

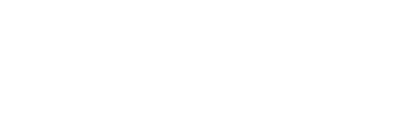

Annual range

Annual variance

VrAnsst

Sea surface salinity (SSS)

Mean annual surface

MeanAnsss

Annual range

RgAnsss

Annual variance

VrAnsss

Minimum monthly

Minsss

Maximum monthly

Maxsss

Chlorophyll a

Silicate

Phosphate
Mean chlorophyll 2007

Chloa07

Mean chlorophyll 2008

Chloa08

Mean chlorophyll 2010

Chloa10

Mean chlorophyll 2012

Surface

Surface

\section{Chloa12}

Sil surface

$\mu \mathrm{mol} .1^{-1}$

NOAA's National

Phos surface

Center for
Psu

Kilometres

${ }^{\circ} \mathrm{C}$

$\mathrm{mg} \cdot \mathrm{m}^{3}$

Giovanni_NASA 
Mean 5 to $35 \mathrm{~m}$

Surface

Mean 5 to $35 \mathrm{~m}$
Phos 535

Nit surface

Nit 535
Environmental

Information

516 Table 2 Values of environmental parameters used in gradient forest modelling for each ecoregion.

\begin{tabular}{|c|c|c|c|c|c|c|c|c|c|c|}
\hline \multirow[t]{2}{*}{ Ecoregion } & \multicolumn{2}{|c|}{$\begin{array}{c}\text { Phosphate }(\mu \text { mol.1 } \\
\left.{ }^{-}\right)\end{array}$} & \multicolumn{3}{|c|}{ Salinity (psu) } & \multirow[t]{2}{*}{$\begin{array}{l}\text { VrAnsst } \\
\left(\mathrm{C}^{\circ}\right)\end{array}$} & \multirow{2}{*}{$\begin{array}{c}\begin{array}{c}\text { Silicate } \\
\left(\mu \mathrm{mol}_{.1} \mathrm{1}^{-1}\right)\end{array} \\
\text { Surf. }\end{array}$} & \multicolumn{2}{|c|}{$\begin{array}{c}\text { Nitrate } \\
\left(\mu \mathrm{mol} .1^{-1}\right)\end{array}$} & \multirow{2}{*}{$\begin{array}{c}\begin{array}{c}\text { Distance to } \\
\text { coastline }\end{array} \\
\text { Mean }\end{array}$} \\
\hline & Surf. & $\begin{array}{c}\text { Mean } \\
5-35 \mathrm{~m}\end{array}$ & Mean & Minsss & Maxsss & & & Surf. & $\begin{array}{c}\text { Mean } \\
5-35 \mathrm{~m}\end{array}$ & \\
\hline 1 & $\begin{array}{l}0.15 \pm \\
0.12- \\
0.15\end{array}$ & $\begin{array}{l}0.14 \pm \\
0.11- \\
0.16\end{array}$ & $\begin{array}{l}35.1 \pm \\
35-35.4\end{array}$ & $\begin{array}{l}34.9 \pm \\
34.8- \\
35.2\end{array}$ & $\begin{array}{l}35.3 \pm 35.17- \\
35.53\end{array}$ & $\begin{array}{l}20.1 \pm 17- \\
27.8\end{array}$ & $\begin{array}{l}1.55 \pm \\
1.31-1.7\end{array}$ & $\begin{array}{l}0.22 \pm \\
0.04- \\
0.25\end{array}$ & $\begin{array}{l}0.14 \pm \\
0.05- \\
0.17\end{array}$ & $15 \pm 1-166$ \\
\hline 2 & $\begin{array}{l}0.13 \pm \\
0.01- \\
0.16\end{array}$ & $\begin{array}{l}0.15 \pm \\
0.1- \\
0.18\end{array}$ & $\begin{array}{l}35.3 \pm \\
35-35.5\end{array}$ & $\begin{array}{l}35.1 \pm \\
34.8- \\
35.3\end{array}$ & $\begin{array}{l}35.43 \pm 35.17- \\
35.67\end{array}$ & $\begin{array}{l}22.3 \pm \\
16.9-35.1\end{array}$ & $\begin{array}{l}1.5 \pm \\
1.11-1.7\end{array}$ & $\begin{array}{l}0.14 \pm \\
0.04- \\
0.25\end{array}$ & $\begin{array}{l}0.11 \pm \\
0.04- \\
0.18\end{array}$ & $30 \pm 1-278$ \\
\hline 3 & $\begin{array}{l}0.12 \pm \\
0.11- \\
0.13\end{array}$ & $\begin{array}{l}0.16 \pm \\
0.13- \\
0.18\end{array}$ & $\begin{array}{l}35.2 \pm \\
35-35.5\end{array}$ & $\begin{array}{l}35 \pm \\
34.9- \\
35.3\end{array}$ & $\begin{array}{l}35.32 \pm 35.12- \\
35.62\end{array}$ & $\begin{array}{l}26.2 \pm \\
17.6-28.9\end{array}$ & $\begin{array}{l}1.39 \pm \\
1.2-1.66\end{array}$ & $\begin{array}{l}0.04 \pm \\
0.036- \\
0.1\end{array}$ & $\begin{array}{l}0.04 \pm \\
0.03- \\
0.11\end{array}$ & $20 \pm 1-81$ \\
\hline 4 & $\begin{array}{l}0.12 \pm \\
0.12- \\
0.13\end{array}$ & $\begin{array}{l}0.16 \pm \\
0.14- \\
0.18\end{array}$ & $\begin{array}{l}35.2 \pm \\
35.1- \\
35.4\end{array}$ & $\begin{array}{l}35.1 \pm \\
35-35.2\end{array}$ & $\begin{array}{l}35.45 \pm 35.27- \\
35.55\end{array}$ & $\begin{array}{l}33 \pm 20.2- \\
37.5\end{array}$ & $\begin{array}{l}1.32 \pm \\
1.23-1.57\end{array}$ & $\begin{array}{l}0.04 \pm \\
0.04- \\
0.08\end{array}$ & $\begin{array}{l}0.04 \pm \\
0.03- \\
0.09\end{array}$ & $7 \pm 1-71$ \\
\hline 5 & $\begin{array}{l}0.15 \pm \\
0.12- \\
0.16\end{array}$ & $\begin{array}{l}0.15 \pm \\
0.13- \\
0.16\end{array}$ & $\begin{array}{l}35.3 \pm \\
35.1- \\
35.5\end{array}$ & $\begin{array}{l}35.1 \pm \\
34.9- \\
35.3\end{array}$ & $\begin{array}{l}35.45 \pm 35.29- \\
35\end{array}$ & $\begin{array}{l}26.1 \pm \\
18.4-28.7\end{array}$ & $\begin{array}{l}1.46 \pm \\
1.31-1.67\end{array}$ & $\begin{array}{l}0.23 \pm \\
0.08- \\
0.25\end{array}$ & $\begin{array}{l}0.15 \pm \\
0.09- \\
0.17\end{array}$ & $95 \pm 3-241$ \\
\hline 6 & $\begin{array}{l}0.1 \pm \\
0.1- \\
0.12\end{array}$ & $\begin{array}{l}0.11 \pm \\
0.1- \\
0.12\end{array}$ & $\begin{array}{l}35.2 \pm \\
35.2- \\
35.4\end{array}$ & $\begin{array}{l}35.1 \pm \\
35.1- \\
35.1\end{array}$ & $\begin{array}{l}35.53 \pm 35.47- \\
35.67\end{array}$ & $\begin{array}{l}22.6 \pm \\
16.8-28.5\end{array}$ & $\begin{array}{l}1.18 \pm \\
1.01-1.45\end{array}$ & $\begin{array}{l}0.052 \pm \\
0.05- \\
0.08\end{array}$ & $\begin{array}{l}0.06 \pm \\
0.06- \\
0.1\end{array}$ & $3 \pm 1-19$ \\
\hline 7 & $\begin{array}{l}0.16 \pm \\
0.15- \\
0.16\end{array}$ & $\begin{array}{l}0.15 \pm \\
0.15- \\
0.16\end{array}$ & $\begin{array}{l}35.3 \pm \\
35.3- \\
35.4\end{array}$ & $\begin{array}{l}35.2 \pm \\
35.1- \\
35.3\end{array}$ & $\begin{array}{l}35.49 \pm 35.42- \\
35.56\end{array}$ & $\begin{array}{l}28 \pm 24.5- \\
29.4\end{array}$ & $\begin{array}{l}1.46 \pm \\
1.31-1.49\end{array}$ & $\begin{array}{l}0.21 \pm \\
0.15- \\
0.25\end{array}$ & $\begin{array}{l}0.15 \pm \\
0.14- \\
0.18\end{array}$ & $\begin{array}{l}173.8 \pm 9- \\
275\end{array}$ \\
\hline 8 & $\begin{array}{l}0.12 \pm \\
0.11- \\
0.15\end{array}$ & $\begin{array}{l}0.14 \pm \\
0.12- \\
0.16\end{array}$ & $\begin{array}{l}35.5 \pm \\
35.3- \\
35.5\end{array}$ & $\begin{array}{l}35.2 \pm \\
35.1- \\
35.3\end{array}$ & $\begin{array}{l}35.6 \pm 35.45- \\
35.67\end{array}$ & $\begin{array}{l}25.6 \pm \\
17.8-30.5\end{array}$ & $\begin{array}{l}1.57 \pm \\
1.34-1.69\end{array}$ & $\begin{array}{l}0.85 \pm \\
0.06- \\
0.25\end{array}$ & $\begin{array}{l}0.1 \pm \\
0.06- \\
0.16\end{array}$ & $9.5 \pm 1-167$ \\
\hline
\end{tabular}

518 Figure 1 Location of sites sampled for fish and local benthic habitat.

520 Figure 2 Overall conditional importance of the environmental predictors of fish $\beta$-diversity on

521 different geographic scales at New Caledonia (a), mainland (b), and Chesterfield-Bellona (c). 
522 The local habitat variables are displayed in green (live coral, dead coral, hard coral, massive

523 and encrusting coral (Mass_Enc_Cor), digitate coral, branching coral, seagrass, macroalgae,

524 sand, gravel, rocks and slab covers).

525

526 Figure 3 a) Mapped gradient forest predictions of fish species turnover in the study area.

527 Insert: Biplot of the biological space of the PCA of assemblage composition with the

528 projection of the main environmental parameters. The colour codes were obtained by

529 matching the colours between the maps and the biplots that display the first factorial plan of

530 the PCA of assemblage composition and the vectors that show the direction and intensity of

531 the seven environmental variables. b) Ecoregions obtained from the clustering of gradient

532 forest outputs. 1: Isolated oceanic reefs, 2: External slopes of the barrier reefs, 3: Remote

533 northern lagoon of the mainland, 4: Southern lagoon of the mainland, 5: South of Chesterfield

534 and north of Bellona, 6: Loyalty Islands, 7: South of Bellona, and 8: Northern lagoon of the

535 mainland.

536 Figure 4 Distribution of nutrient concentrations and physical parameters in each ecoregion.

537 The colour of each boxplot corresponds to the colours of the ecoregions in Fig. 3b. The

538 middle black line in each box corresponds to the median value of the parameter.

539

540 Figure 5 Left side of each plot: Importance of the environmental predictors in explaining the

541 fish $\beta$-diversity at the site. Right side of each plot: Radar plots that indicate the relative mean

542 value of each local habitat variable, which were obtained by rescaling the variable to a $0 \%$ to

$543100 \%$ range based on its absolute range of values in the overall data set. This approach

544 enabled the comparison of the thirteen variables across the eight sites. 


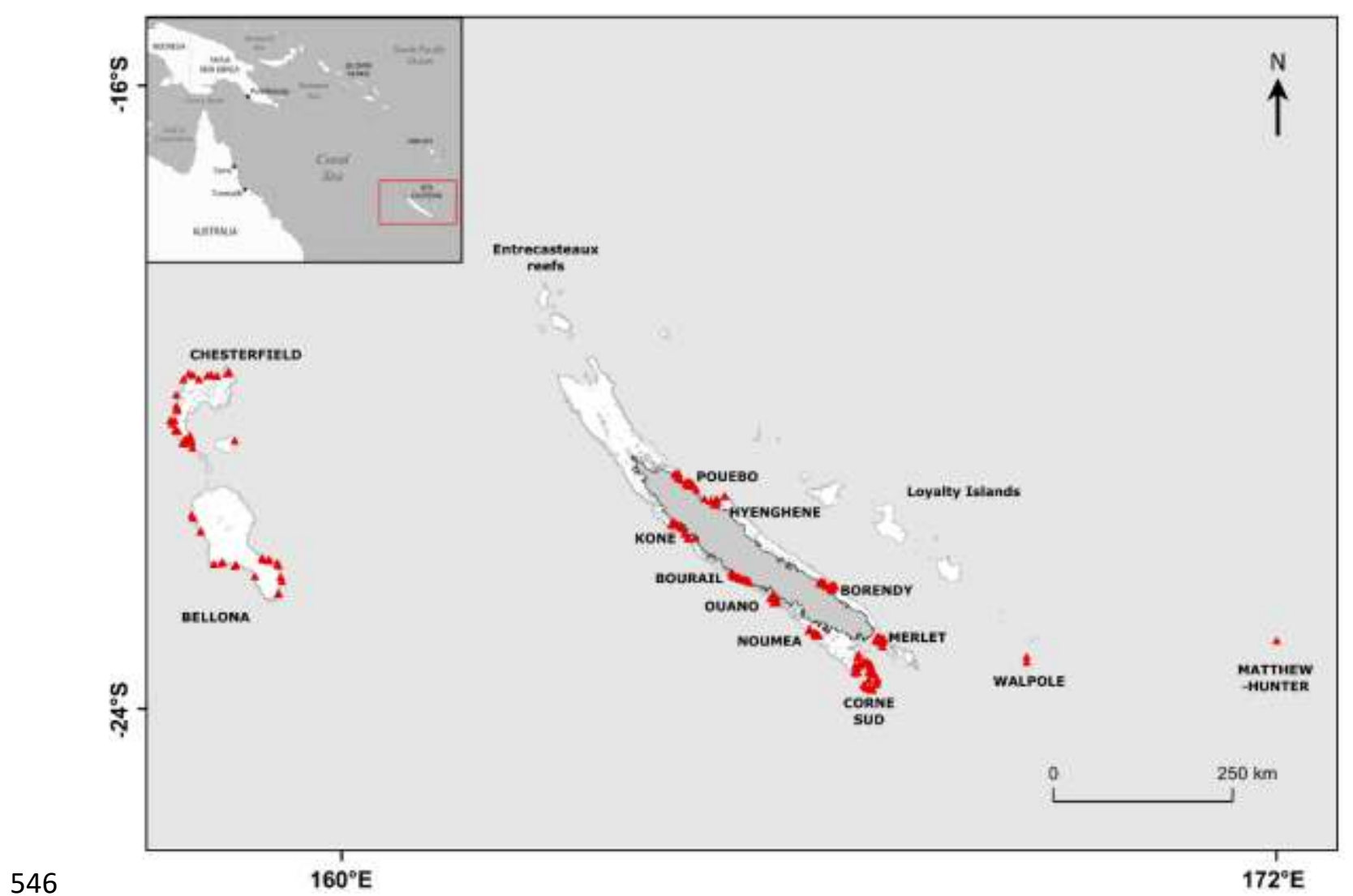

547 Figure 1 

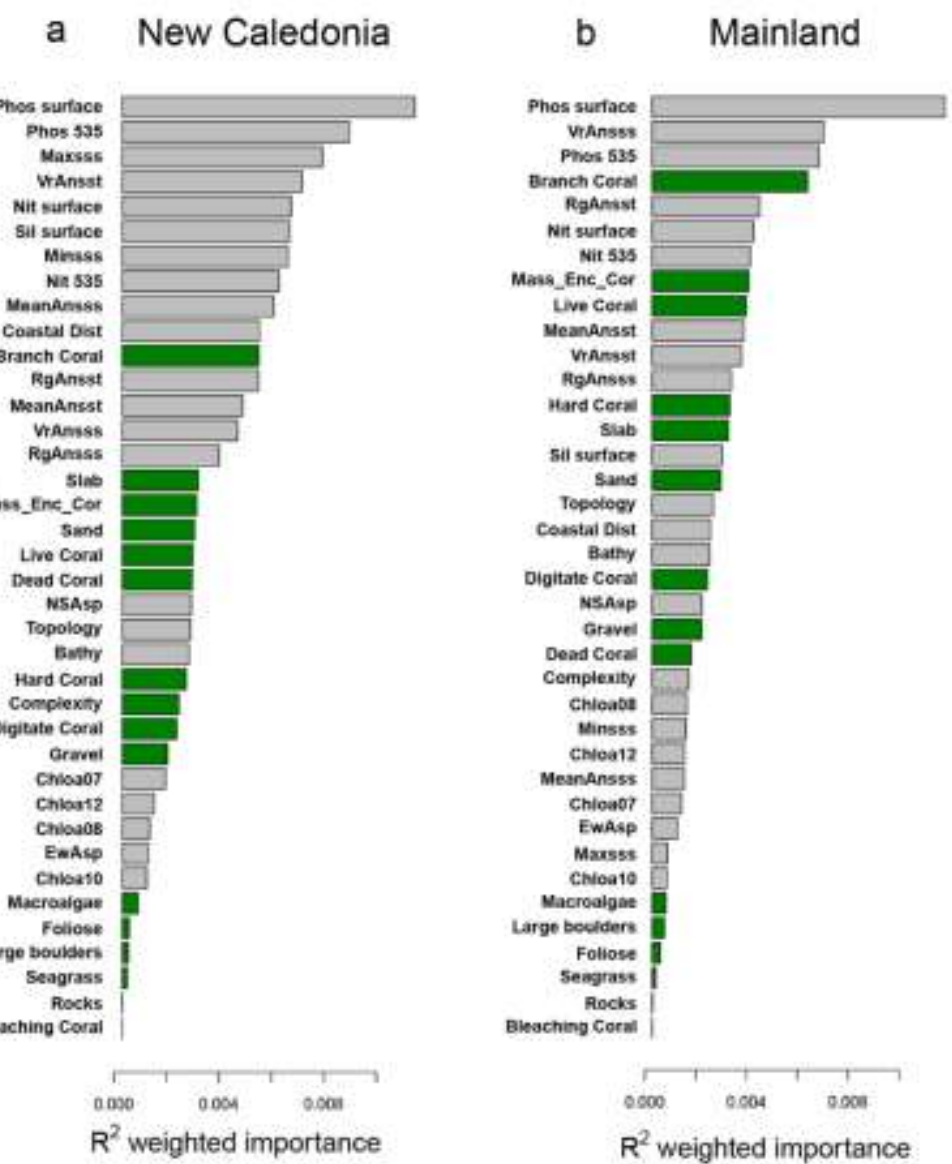

\section{c Chesterfield-Bellona}

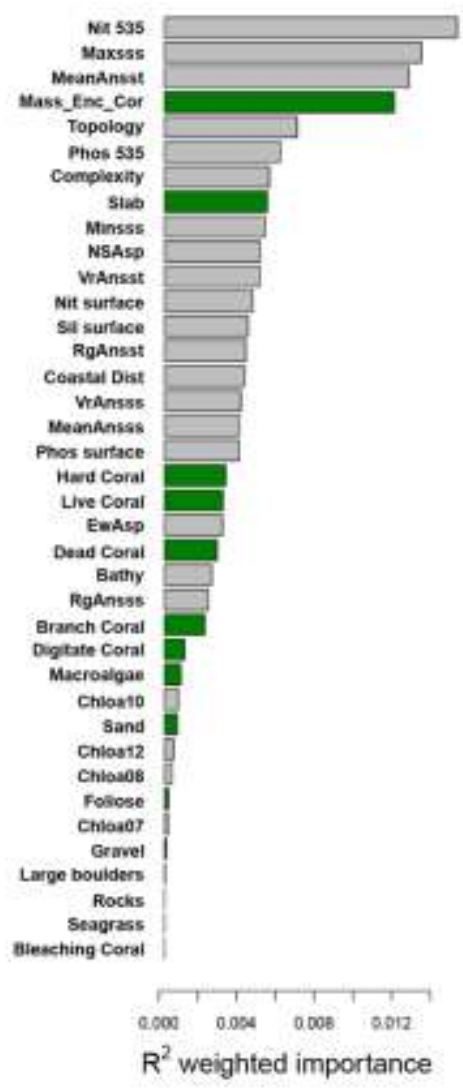

$549 \quad$ Figure 2 

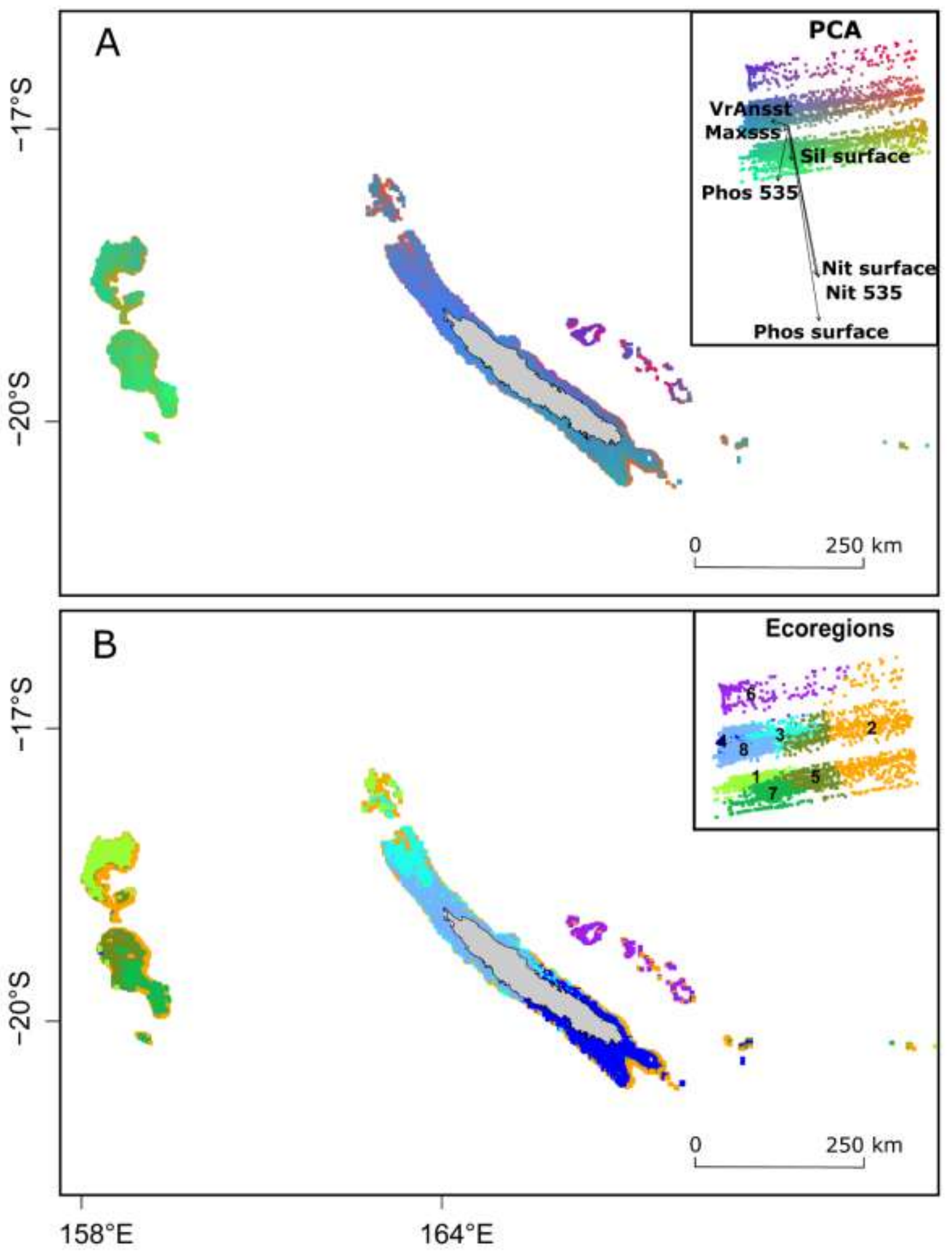

550

$551 \quad$ Figure 3 

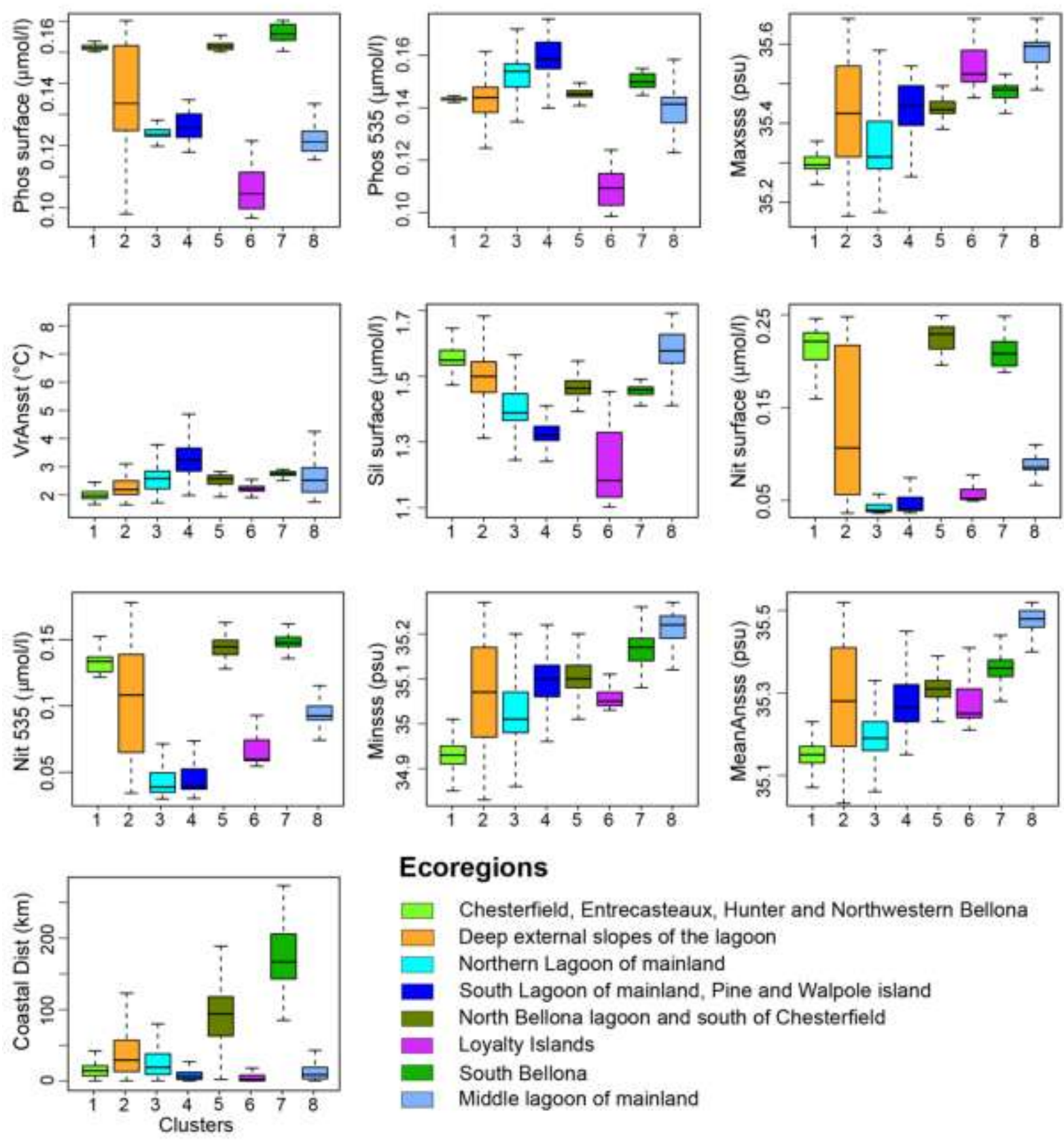

\section{Ecoregions}

Chesterfield, Entrecasteaux, Hunter and Northwestern Bellona Deep external slopes of the lagoon

Northern Lagoon of mainland

South Lagoon of mainland, Pine and Walpole island

North Bellona lagoon and south of Chesterfield

Loyalty Islands

South Bellona

Middle lagoon of mainland

Figure 4 


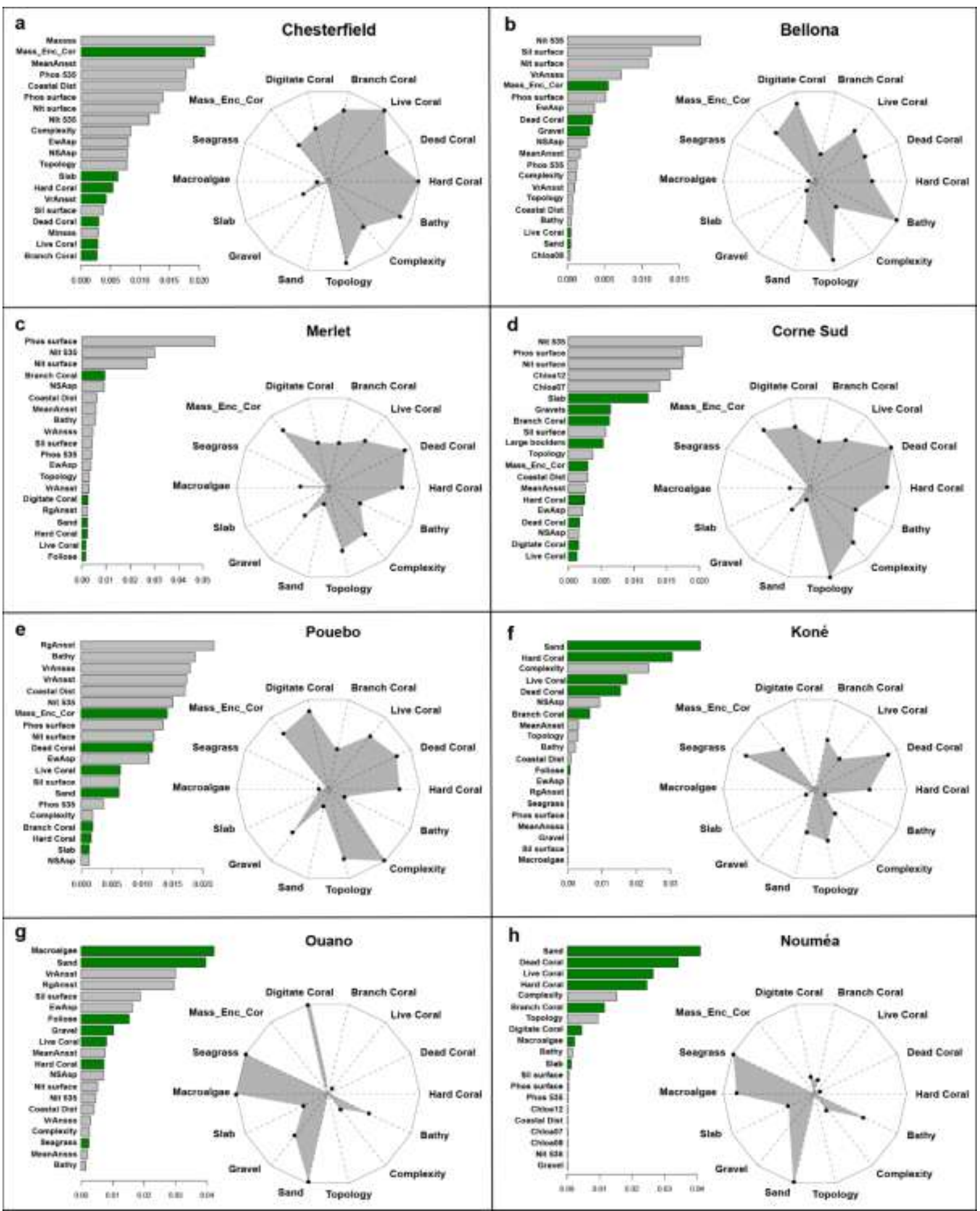

$555 \quad$ Figure 5

\section{REFERENCES}

Airoldi, L., Balata, D., \& Beck, M.W. (2008) The Gray Zone: Relationships between habitat loss and marine diversity and their applications in conservation. Journal of Experimental Marine Biology and Ecology, 366, 8-15. 
Allgeier, J.E., Burkepile, D.E., \& Layman, C.A. (2017) Animal pee in the sea: consumer-mediated nutrient dynamics in the world's changing oceans. Global Change Biology, 23, 2166-2178.

Anderson, M.J., Crist, T.O., Chase, J.M., Vellend, M., Inouye, B.D., Freestone, A.L., Sanders, N.J., Cornell, H.V., Comita, L.S., Davies, K.F., Harrison, S.P., Kraft, N.J.B., Stegen, J.C., \& Swenson, N.G. (2011) Navigating the multiple meanings of $\beta$ diversity: a roadmap for the practicing ecologist: Roadmap for beta diversity. Ecology Letters, 14, 19-28.

Andréfouët, S., Cabioch, G., Flamand, B., \& Pelletier, B. (2009) A reappraisal of the diversity of geomorphological and genetic processes of New Caledonian coral reefs: a synthesis from optical remote sensing, coring and acoustic multibeam observations. Coral Reefs, 28, 691707.

Baker, M.R. \& Hollowed, A.B. (2014) Delineating ecological regions in marine systems: Integrating physical structure and community composition to inform spatial management in the eastern Bering Sea. Deep Sea Research Part II: Topical Studies in Oceanography, 109, 215-240.

Barton, P.S., Cunningham, S.A., Manning, A.D., Gibb, H., Lindenmayer, D.B., \& Didham, R.K. (2013) The spatial scaling of beta diversity: Spatial scaling of beta diversity. Global Ecology and Biogeography, 22, 639-647.

Baselga, A. (2010) Partitioning the turnover and nestedness components of beta diversity: Partitioning beta diversity. Global Ecology and Biogeography, 19, 134-143.

Bellwood, D.R. \& Wainwright, P.C. (2002) The history and biogeography of fishes on coral reefs. Coral Reef Fishes: Dynamics and Diversity in a Complex Ecosystem pp. 5-32. Academic Press, Boston, MA, USA.

Belmaker, J. (2009) Species richness of resident and transient coral-dwelling fish responds differentially to regional diversity. Global Ecology and Biogeography, 18, 426-436.

Belmaker, J., Ziv, Y., Shashar, N., \& Connolly, S.R. (2008) Regional variation in the hierarchical partitionning of diversitu in coral-dwelling. Ecology, 89, 2829-2840.

Borsa, P., Pandolfi, M., Andréfouët, S., \& Bretagnolle, V. (2010) Breeding Avifauna of the Chesterfield Islands, Coral Sea: Current Population Sizes, Trends, and Threats. Pacific Science, 64, 297314.

Breiman, L. (2001) Random forests. Machine learning, 45, 5-32.

Burkepile, D.E. \& Hay, M.E. (2006) Herbivore vs. nutrient control of marine primary producers: context-dependent effects. Ecology, 87, 3128-3139.

Cardoso, P., Aranda, S.C., Lobo, J.M., Dinis, F., Gaspar, C., \& Borges, P.A.V. (2009) A spatial scale assessment of habitat effects on arthropod communities of an oceanic island. Acta Oecologica, 35, 590-597.

Ceccarelli, D.M., McKinnon, A.D., Andréfouët, S., et al. (2013) The Coral Sea. Advances in Marine Biology pp. 213-290. Elsevier,

Chabanet, P., Dufour, V., \& Galzin, R. (1995) Disturbance impact on reef fish communities in Reunion Island (Indian Ocean). Journal of Experimental Marine Biology and Ecology, 188, 29-48. 
Clua, E., Chauvet, C., Mourier, J., Werry, J.M., \& Randall, J.E. (2015) Pattern of movements within a home reef in the Chesterfield Islands (Coral Sea) by the endangered Giant Grouper, Epinephelus lanceolatus. Aquatic Living Resources, 28, 53-58.

Clua, E., Legendre, P., Vigliola, L., Magron, F., Kulbicki, M., Sarramegna, S., Labrosse, P., \& Galzin, R. (2006) Medium scale approach (MSA) for improved assessment of coral reef fish habitat. Journal of Experimental Marine Biology and Ecology, 333, 219-230.

Cutler, D.R., Edwards, T.C., Beard, K.H., Cutler, A., Hess, K.T., Gibson, J., \& Lawler, J.J. (2007) Random forest for classification in ecology. Ecology, 88, 2783-2792.

Delvinquier \& Jegat (2001) Historique des mines de phosphate en Nouvelle-Calédonie. Bulletin de la Société de l'Etudes Historiques de la Nouvelle Calédonie, 128, 41-80.

Ekman, S., P. (1953) Zoogeography of The Sea. Sidgwick and Jackson, London,

Ellis, N., Smith, S.J., \& Pitcher, C.R. (2012) Gradient forests: calculating importance gradients on physical predictors. Ecology, 93, 156-168.

Ferraris, J., Pelletier, D., Kulbicki, M., \& Chauvet, C. (2005) Assessing the impact of removing reserve status on the Abore Reef fish assemblage in New Caledonia. Marine Ecology Progress Series, 292, 271-286.

Ferrier, S., Manion, G., Elith, J., \& Richardson, K. (2007) Using generalized dissimilarity modelling to analyse and predict patterns of beta diversity in regional biodiversity assessment. Diversity and Distributions, 13, 252-264.

Fichez, R., Adjeroud, M., Bozec, Y.-M., Breau, L., Chancerelle, Y., Chevillon, C., Douillet, P., Fernandez, J.-M., Frouin, P., Kulbicki, M., Moreton, B., Ouillon, S., Payri, C., Perez, T., Sasal, P., \& Thébault, J. (2005) A review of selected indicators of particle, nutrient and metal inputs in coral reef lagoon systems. Aquatic Living Resources, 18, 125-147.

Foster, N., Box, S., \& Mumby, P. (2008) Competitive effects of macroalgae on the fecundity of the reef-building coral Montastraea annularis. Marine Ecology Progress Series, 367, 143-152.

Friedlander, A., Sandin, S., DeMartini, E., \& Sala, E. (2010) Spatial patterns of the structure of reef fish assemblages at a pristine atoll in the central Pacific. Marine Ecology Progress Series, 410, 219-231.

Gove, J.M., McManus, M.A., Neuheimer, A.B., Polovina, J.J., Drazen, J.C., Smith, C.R., Merrifield, M.A., Friedlander, A.M., Ehses, J.S., Young, C.W., Dillon, A.K., \& Williams, G.J. (2016) Near-island biological hotspots in barren ocean basins. Nature Communications, 7, 10581.

Growns, I. (2009) Differences in bioregional classifications among four aquatic biotic groups: Implications for conservation reserve design and monitoring programs. Journal of Environmental Management, 90, 2652-2658.

Khalaf, M.. \& Kochzius, M. (2002) Changes in trophic community structure of shore fishes at an industrial site in the Gulf of Aqaba, Red Sea. Marine Ecology Progress Series, 239, 287-299.

Kittinger, J.N., Dowling, A., Purves, A.R., Milne, N.A., \& Olsson, P. (2011) Marine Protected Areas, Multiple-Agency Management, and Monumental Surprise in the Northwestern Hawaiian Islands. Journal of Marine Biology, 2011, 1-17. 
Koubbi, P., Moteki, M., Duhamel, G., Goarant, A., Hulley, P.-A., O’Driscoll, R., Ishimaru, T., Pruvost, P., Tavernier, E., \& Hosie, G. (2011) Ecoregionalization of myctophid fish in the Indian sector of the Southern Ocean: Results from generalized dissimilarity models. Deep Sea Research Part II: Topical Studies in Oceanography, 58, 170-180.

Kuffner, I., Walters, L., Becerro, M., Paul, V., Ritson-Williams, R., \& Beach, K. (2006) Inhibition of coral recruitment by macroalgae and cyanobacteria. Marine Ecology Progress Series, 323, 107117.

Kulbicki, M. (1997) Results of ten years of research (1985-1995) by ORSTOM on diversity, density, biomass, and community trophic structure of the lagoon and reef fishes in New Caledonia. Cybium, 21, 47-79.

Kulbicki, M., Parravicini, V., Bellwood, D.R., Arias-Gonzàlez, E., Chabanet, P., Floeter, S.R., Friedlander, A., McPherson, J., Myers, R.E., Vigliola, L., \& Mouillot, D. (2013) Global Biogeography of Reef Fishes: A Hierarchical Quantitative Delineation of Regions. PLOS ONE, 8, e81847.

Lasram, F.B.R., Hattab, T., Halouani, G., Romdhane, M.S., \& Le Loc'h, F. (2015) Modeling of Beta Diversity in Tunisian Waters: Predictions Using Generalized Dissimilarity Modeling and Bioregionalisation Using Fuzzy Clustering. PLOS ONE, 10, e0131728.

Leaper, R., Hill, N.A., Edgar, G.J., Ellis, N., Lawrence, E., Pitcher, C.R., Barrett, N.S., \& Thomson, R. (2011) Predictions of beta diversity for reef macroalgae across southeastern Australia. Ecosphere, 2, art73.

Littler, M.M., Littler, D.S., \& Brooks, B.L. (2006) Harmful algae on tropical coral reefs: Bottom-up eutrophication and top-down herbivory. Harmful Algae, 5, 565-585.

Lourie, S.A. \& Vincent, A.C.J. (2004) Using Biogeography to Help Set Priorities in Marine Conservation. Conservation Biology, 18, 1004-1020.

Mallet, D., Vigliola, L., Wantiez, L., \& Pelletier, D. (2016) Diurnal temporal patterns of the diversity and the abundance of reef fishes in a branching coral patch in New Caledonia. Austral Ecology, 41, 733-744.

Martiny, J.B.H., Eisen, J.A., Penn, K., Allison, S.D., \& Horner-Devine, M.C. (2011) Drivers of bacterial $\beta$ diversity depend on spatial scale. Proceedings of the National Academy of Sciences, 108, 7850-7854.

McCauley, D.J., DeSalles, P.A., Young, H.S., Dunbar, R.B., Dirzo, R., Mills, M.M., \& Micheli, F. (2012) From wing to wing: the persistence of long ecological interaction chains in less-disturbed ecosystems. Scientific Reports, 2, 409.

McCoy, E.D. \& Bell, S.S. (1991) Habitat structure: The evolution and diversification of a complex topic. Habitat Structure (ed. by S.S. Bell, E.D. McCoy, and H.R. Mushinsky), pp. 3-27. Springer Netherlands, Dordrecht.

McKnight, M.W., White, P.S., McDonald, R.I., Lamoreux, J.F., Sechrest, W., Ridgely, R.S., \& Stuart, S.N. (2007) Putting Beta-Diversity on the Map: Broad-Scale Congruence and Coincidence in the Extremes. PLoS Biology, 5, e272. 
Messmer, V., Jones, G.P., Munday, P.L., Holbrook, S.J., Schmitt, R.J., \& Brooks, A.J. (2011) Habitat biodiversity as a determinant of fish community structure on coral reefs. Ecology, 92, 22852298.

Mourier, J., Maynard, J., Parravicini, V., Ballesta, L., Clua, E., Domeier, M.L., \& Planes, S. (2016) Extreme Inverted Trophic Pyramid of Reef Sharks Supported by Spawning Groupers. Current Biology, 26, 2011-2016.

Mumby, P. \& Steneck, R. (2008) Coral reef management and conservation in light of rapidly evolving ecological paradigms. Trends in Ecology \& Evolution, 23, 555-563.

Nakazawa, M. (2014) Functions for medical statistics book with some demographic data. http://CRAN.R-project.org/package=fmsb. $R$ package version 0.5.1, .

Pelletier, D., Leleu, K., Mallet, D., Mou-Tham, G., Hervé, G., Boureau, M., \& Guilpart, N. (2012) Remote High-Definition Rotating Video Enables Fast Spatial Survey of Marine Underwater Macrofauna and Habitats. PLOS ONE, 7, e30536.

Pitcher, R.C., Lawton, P., Ellis, N., Smith, S.J., Incze, L.S., Wei, C.-L., Greenlaw, M.E., Wolff, N.H., Sameoto, J.A., \& Snelgrove, P.V.R. (2012) Exploring the role of environmental variables in shaping patterns of seabed biodiversity composition in regional-scale ecosystems: Environmental shaping of seabed biodiversity. Journal of Applied Ecology, 49, 670-679.

Powell, A., Pelletier, D., Jones, T., \& Mallet, D. (2016) The impacts of short-term temporal factors on the magnitude and direction of marine protected area effects detected in reef fish monitoring. Global Ecology and Conservation, 8, 263-276.

Rahbek, C. (2005) The role of spatial scale and the perception of large-scale species-richness patterns. Ecology Letters, 8, 224-239.

Sale, P.F. (1998) Appropriate spatial scales for studies of reef-fish ecology. Austral Ecology, 23, 202208.

Sbrocco, E.J. \& Barber, P.H. (2013) MARSPEC: ocean climate layers for marine spatial ecology: Ecological Archives E094-086. Ecology, 94, 979-979.

Spalding, M.D., Fox, H.E., Allen, G.R., Davidson, N., FerdañA, Z.A., Finlayson, M., Halpern, B.S., Jorge, M.A., Lombana, A., Lourie, S.A., Martin, K.D., Mcmanus, E., Molnar, J., Recchia, C.A., \& Robertson, J. (2007) Marine Ecoregions of the World: A Bioregionalization of Coastal and Shelf Areas. BioScience, 57, 573.

Stevenson, C., Katz, L.S., Micheli, F., Block, B., Heiman, K.W., Perle, C., Weng, K., Dunbar, R., \& Witting, J. (2007) High apex predator biomass on remote Pacific islands. Coral Reefs, 26, 4751.

Tanner, J.E. (1995) Competition between scleractinian corals and macroalgae: An experimental investigation of coral growth, survival and reproduction. Journal of Experimental Marine Biology and Ecology, 190, 151-168.

Thomson, R.J., Hill, N.A., Leaper, R., Ellis, N., Pitcher, C.R., Barrett, N.S., \& J. Edgar, G. (2014) Congruence in demersal fish, macroinvertebrate, and macroalgal community turnover on shallow temperate reefs. Ecological Applications, 24, 287-299. 


\section{BIOSKETCH}

715 The AMBIO project aims to provide data and methodologies for a comprehensive assessment

716 of biodiversity and resources (mostly fish and habitats) in New Caledonia, at both local and

717 large scales. A large data set of more than 3,000 observations that covers most New Caledonia

718 reefs and associated habitats has been collected using remote unbaited rotating underwater

719 video (STAVIRO). The project is conducted in close collaboration with management

720 practitioners and has a strong capacity-building component.

721 Author contributions: J.G. and D.P. conceived the study. D.P., L.C. and W.R. collected field

722 data. L.C. and W.R. extracted data from video samples. J.G. and T.B. conducted statistical

723 analyses of the data. J.G. interpreted the results and wrote the manuscript with the assistance

724 of D.P.

725 Editor: Luiz Rocha 